\title{
Erotismo, Cultura y Sujeto en De Donde Son los Cantantes
}

A pesar de su evidente carácter lúdico, o tal vez a causa de él, De donde son los cantantes es un texto que suscita, mediante su propia constitución, preguntas importantes sobre los fundamentos de la literatura. La brevedad de De donde son los cantantes es la primera de varias trampas que parecen invitar a una lectura frìvola. Pero $D e$ donde son los cantantes exige, por el contrario, una lectura detenida, que dé cuenta de los innumerables pliegues y repliegues de un texto cuya economía enmascara una serie de intricadas relaciones formales. En el presente trabajo se hará una lectura detallada de esta novela de Sarduy para analizar tanto las preguntas que ésta suscita como la complicada red de significación que la compone. Tres tópicos básicos informarán este análisis: la relación entre el erotismo y la actividad de escribir, la noción de cultura como sistema totalizante en el cual se inscribe la obra, y la cuestión del ser, del sujeto que la actividad literaria tradicionalmente implica.

La actividad de escritura genera en De donde son los cantantes tres polaridades, siendo la primera, la relación entre palabra/deseo, que permite el desplazamiento de las categorias asociadas con la literatura a lo largo del tex to. Una nueva idea de la función del lenguaje motiva la cadena de artificios verbales que compone el texto. Según Foucault, en el signo clásico, la palabra incluía la idea de la representación de un contenido dentro de sỉ: habỉa una adecuación lógica entre el significado primario y su correspondiente expresión en un significante que reflejaba, a la vez, su propia función representativa. ${ }^{1}$ Esta relación armónica se quiebra en la época moderna, cuando se rompe el eje de la relación significado/significante debido a la transformación del concepto de "centro" transcendental. 2 Por lo tanto, el 
significante se erige en función primordial en la producción del sentido. La relación unidimensional de los términos del signo clásico es reemplazada por la relación multidimensional de suma de significantes, que produce múltiples niveles de sentido. ${ }^{3}$ Para Sarduy, esta escritura producida por el exceso de significantes es neobarroca, eco del barroco del siglo XVII. La diferencia entre los dos órdenes del lenguaje, la representación, por una parte, y el juege verbal, por otra, produce igualmente dos sistemas de figuración metafórica. La figura retórica neobarroca va a suscitar la relación entre palabra y deseo, base del texto de De donde son los cantantes.

En el orden clásico, la lógica de la representación se expresa a través de la metáfora plena, circular, en la cual existe una relación de propiedad entre los términos que aproxima. $4 \mathrm{En}$ el orden neobarroco, la figura poética quiebra la armonía del círculo para formar la elipsis: dos centros generados por la falta de adecuación entre significado y significante en cada término. 5 La escritura barroca se caracteriza por la estructuración a través de figuras retóricas, como la elipsis, la parábola, la antítesis -figuras que revelan en su propia constitución la ausencia de un significado transcendente, y que producen un sentido con el significante que "sobra."6 Esta carencia/exceso en la base del barroco destaca el carácter erótico del lenguaje. En el barroco del siglo XVII, los términos de las metáforas -la luz y la obscuridad- aludían a elementos escatológicos y a la muerte. En el neobarroco, las figuras indican la búsqueda del objeto perdido: el vacío en la función del lenguaje y el "objeto parcial" erótico.7 La escritura se hace una actividad erótica, ya que es puro exceso, superficie, y materialidad. Al igual que la sexualidad productiva, que sirve el fin de la procreación, la escritura clásica servía una función comunicativa, al expresar un sentido transcendente. El erotismo lúdico, por el contrario, es juego, recreo, teatro, igual que la escritura neobarroca, cuyo juego de significantes tampoco sirve una finalidad. 8

La inscripción de figuras retóricas, en el vacío de la página, provoca el erotismo verbal, que se reproduce a nivel textual, estableciendo el vínculo entre palabra/deseo. El cuerpo de la figura elíptica traza el cuerpo del texto: "La figuration serait le mode d'apparition du corps érotique dans le profil du texte." 9 Al nivel verbal, el movimiento en parábola de los significantes, continuamente indica la carencia de un sentido original. Este deseo de significación nunca es consumado, ya que se prolonga infinitamente en el juego verbal. Al nivel textual, este mismo deseo, producido por la palabra, impulsa el movimiento de los cuerpos fabricados por la narración. Las Parcas, el 
General, Dolores y Flor, son "cuerpos" siempre en busca del objeto del deseo, y, simultáneamente, son objetos de éste. La configuración de este deseo, textual, reproduce la figura parabólica de la palabra: un falso ser (centro, sujeto ausente) persigue a otro, sin alcanzar la consumación del deseo. De la misma manera que la palabra nunca recupera el significado, el sujeto (falso) siempre se desliza en busca del otro, falso sujeto, que es, a la vez, objeto.

De ahï que la escritura en Sarduy se haga una especie de travestismo, emblema de la relación entre palabra y deseo, como él mismo ha expresado en Escrito sobre un cuerpo. El significado esencial falta en la palabra como la clara definición sexual falta en el sujeto. Ambas carencias se suplen por la multiplicidad de significados eróticos -a nivel gráfico, por la figura retórica- a nivel textual, por la parábola de la persecución del objeto del deseo. Convertidos en objetos de la búsqueda erótica, los sujetos, los entes del texto se metamorfosean continuamente: cambian de sexo, de apariencia exterior. Esta falta de sentido esencial y de sexualidad fija se escamotea a través de la comercialización del deseo, y por la oposición entre indulgencia y asceticismo extremados (expresiones del deseo en la raza blanca, vistas en "La entrada de Cristo en La Habana"). En total, el texto de De donde son los cantantes forma un sistema de escritura "somática": cuerpo/tex to creado por el deseo verbal, que motiva el deseo de los cuerpos inscritos en el mismo lenguaje. Esta relación genera, a la vez, una nueva equivalencia: "Esos planos de intersexualidad son análogos a los planos de intertextualidad que constituyen el objeto literario."10 En consecuencia, la escritura se hace travestismo -máscara que esconde la falta de sentido y su doble, la falta de sexualidad determinante. 11

Esta escritura somática produce, entonces, un primer plano que es la equivalencia entre tex to y cuerpo; pero este último está superimpuesto en un conjunto cultural. El cuerpo es la sintesis de la cultura cubana, definida en "Curriculum cubense," la sección inicial de la novela. Las tres razas -blanca, negra, china- que componen el mosaico cultural de Cuba causan la división del texto en tres partes. ${ }^{12}$ A la vez, las razas forman una figura corpórea, junto con la $\mathrm{Nada}$ o la Muerte. Este cuarto elemento sugiere la Nada como categorỉa filosófica, al mismo tiempo que señala una metáfora de la escritura. En "Curriculum cubense," se forma primero una figura compuesta por el binomio el General y Auxilio, más la Nada, figura circular de una culebra que se muerde la cola. ${ }^{13} \mathrm{El}$ tex to de la Cuba ausente toma cuerpo en la próxima figura de los cuatro seres, 
"trébol, signo yoruba o animal de cuatro cabezas" (20), al unirse el binomio y la Nada con la china y la negra.

Por medio de la inscripción de figuras retóricas, el cuerpo de $D e$ donde son los cantantes cambiará según la raza que lo forma. Cada raza tendrá un lenguaje propio - la china, metafórico, la negra, coloquial, la blanca, retórico (histórico-literario) - para componer un cuerpo particular. El movimiento de inscripción del tex to para forjar estos cuerpos raciales se condensa en la última parte, titulada "La entrada de Cristo en La Habana." Auxilio, movida por el deseo del General/Cristo, quiere que la gente de Las Villas lo/la reciba, ya que es la carne hecha verbo (137), versión irrisoria del Cristo tradicional, que es el Verbo encarnado. En un momento de desesperación, quiere hacer de su cuerpo el texto (lugar de lectura) de Cristo, por medio de la inscripción de la palabra en su propia carne. Declara Auxilio: "Haré de mi cuerpo Tu libro/ ¡leerán de mí!" (137). El cuerpo de Auxilio, grabado por la palabra, se hace texto, igual que el texto mismo se hace cuerpo por la cifra de figuras retóricas, raciales. La configuración de estas figuras en forma parabólica sirve como móvil para la producción del deseo, de los cuerpos en el texto.

En la parte china, "Junto al río de Cenizas de Rosa," las metáforas crean el ambiente de la escena, caracterizada por los dos principios del erotismo chino, el "yin" y el "yang".14 Para crear una atmósfera parecida a la de una pintura china, predominan elementos naturales junto con un mutismo en las imágenes. Los animales escogidos para esta figuración son tomados de la mitología china: la tortuga y el unicornio son animales que representan la longevidad.15 La escena del primer encuentro entre el General y Flor se desenvuelve en el contexto de esta pintura china creada por el lenguaje metafórico. Como principio femenino del "yin," la presencia de Flor se describe por medio de la metáfora, inscrita en el paisaje mudo: "Cosida en aquel paisaje, ejercitando su yin en pleno bosque de La Habana, era un pájaro blanco detrás del bambú, un prisionero inmóvil entre lanzas" (25). De repente, la aparición del General causa una violenta irrupción dentro de esta escena pacífica y estática. La agresividad del General, representante del principio masculino del "yang," se describe, en cambio, por una sinécdoque: "Asî la sorprendió el humito de Romeo y Julieta, el mejor de los tabacos habanos, y el medalleo" (25). La diferencia de figuración poética entre los dos cuerpos refleja la oposición entre los principios del erotismo chino. Flor, pasiva, espera en la metáfora -en cambio, la fuerza erótica 
concentrada en el falo del General, se desplaza por la metonimia, a sus otras caracterǐsticas fïsicas.

En la continuación de la escena, los dos modos de figuración acentúan el creciente deseo del General y la correspondiente lejanía de Flor. Metáfora del falo, "como con un machete doble," (26), a la vez metonimia del deseo, " ¡flautica pïrrica ésa!" (27), intensifican la exitación del General, mientras que Flor es "una máscara blanca, ... el vuelo de una paloma, el rastro de un conejo" (26). El despliegue de las figuras hace que el encuentro inicial se convierta en una verdadera batalla. Con la intensificación del deseo del General, la escena de persecución llega a su apogeo, pero Flor, "textura," (26) logra escaparse. La Cenizas de Rosa es como el lenguaje que ha suscitado todo este encuentro, y lo ha dejado sin la conclusión esperada, por el General, por el lector. Por eso, el tiempo de la batalla corresponde al "tiempo de una recitación" (26), tiempo verbal de la praxis, de la performance del texto, en el sentido lingüistico e histriónico. La batalla es teatral, porque ocurre en ese espacio/tiempo verbal de la producción del lenguaje/deseo en figuras poéticas.

Desde esta escena inicial, el paisaje chino se mezcla con elementos cubanos: el Palacio de Verano se vuelve el Bosque de la Habana (que en realidad no era tal, sino un parque) -el rî́o Yang-Tzé es el Almendares (27). Ninguno de los ambientes aludidos son verïdicos, sino, al contrario, son parodia, irrisión, eco borrado. Dentro de esta doble escenografía se desenvolverá el movimiento del deseo del General, en el Teatro Changai (burlesco chino-cubano), y/o la Opera china (29), superposición que refleja los dos planos culturales recordados por la palabra.

La persecución del General del objeto de su deseo formará una parábola sádica:

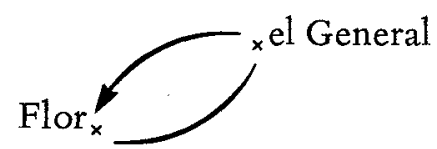

Dentro de esta figura, el General irá de "mirón a sádico" (53) y matará a Flor, objeto nunca alcanzado. La dirección de la parábola la indica el movimiento "en diagonal" (31) del General en su búsqueda de Flor. En esta primera etapa, éste simplemente se satisface viendo la función de teatro en que Flor aparece, ya que "el héroe sádico espera que la representación de esta escena coincida con la urgencia 
de su deseo."16 Ya incitado, su deseo se convierte en fetichismo -se pasma ante la ropa interior de la china (32-33). Esta nueva metonimia del deseo, ansia de posesión de un objeto que pertenece al objeto del deseo, va a impulsar la destrucción final.17 La audacia del General se interrumpe por la aparición de las Parcas, coristas de la Opera, transformadas por el semen, "arroyo albino," (35) del General, que les causa una serie de metamorfosis. Inversión de la metonimia erótica inicial, el fetichismo del General se convierte en perversión, al satisfacer su deseo con las Parcas ansiosas (38).

Esta repetición del acto, base del movimiento sádico, incita aun más el deseo de Flor en el español.18 Esta ansia erótica es tan inalcanzable como la falta que impulsa la repetición del significante en el movimiento de significación. Igual que la distancia creada en el barroco entre los dos polos del signo, la imaginación del perverso sufre "una falla entre la realidad y el deseo."19 La falta es motivada porque el deseo de Flor está vacio de significado -ella es impostura, "una ausencia pura" (38), un travestî. La sexualidad de Flor es tan falsa como el acto cometido por el General con las Parcas. Deseo de un objeto falso, de una máscara, que reproduce el escamoteo del lenguaje- la figura sádica, entonces, repite la función de la escritura como travestismo.

Antes de completar la parábola, el General repite el movimiento de su deseo con la doble de Flor, la china/cubana Marĭa Eng, al convertirse de nuevo en mirón. Ya después de ser víctima de otro sádico, con el castigo recibido de Carita de Tortura, el General está por completar su figura. Otra vez la repetición agónica, de los actos, típica del sadismo: el General regresa al Changai a presenciar, por última vez, la Toma del Fuerte. En ese momento siente la esencia -falsa- del objeto de su deseo, y en esta desesperación logra aniquilarlo. La figura se completa con la muerte del objeto erótico, como consecuencia de ese movimiento insatisfecho del fetichismo y del sadismo: "Es cierto: G. habỉa terminado su parábola, cumplido su ciclo. De mirón a sádico. Quien posee por la mirada posee por la daga" (53). Esta parábola sádica-textual china reproduce el movimiento de desplazamiento de la figura retórica barroca. Flor, centro ausente, falso objeto del deseo, es perseguida por el General, centro presente, (falso) sujeto que desea. La repetición sádica intensifica el movimiento de persecución del objeto/fetiche inalcanzable. En el momento de éxtasis la figura elíptica se completa, al mismo tiempo que se destruye el objeto erótico. De igual manera, la escritura se autodestruye en negatividad en el momento en que se termine la 
lectura. El deseo conduce a la muerte, igual que la escritura conlleva a la nada. El binomio producido, deseo/muerte, servirá de apoyo a cada figura erótica en las otras dos partes de De donde son los cantantes.

En "La Dolores Rondón," la figura del deseo es igualmente parabólica, pero asume una forma doble, ya que la carrera de la mulata va a trascribir dos movimientos elípticos. Primero, la parábola del poder será formada por el movimiento lineal y vertical de la provincia a la capital, junto con la línea horizontal de la pobreza a la riqueza:

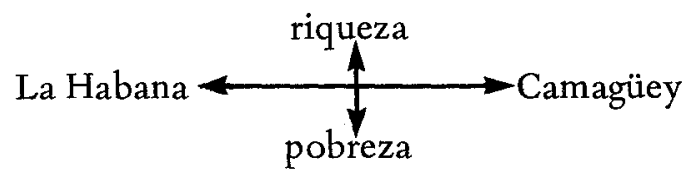

La ambición de Dolores de ser famosa le hace usar el deseo sexual para satisfacer el otro, y más fuerte, deseo del poder, a través de su unión amorosa con Mortal Pérez, (el General), político provinciano que llegará a ser senador en la capital. Junto con la figura de ascensión al poder, está la "parábola de los animales," que explicará la caída de la mulata. Basada en un proverbio popular, el orden de esta parábola es la sucesión jerárquica del poder, como lo indica el título del poema de Wallace Stevens, a que alude el texto de Sarduy: "Frogs eat butterflies. Snakes eat frogs. Hogs eat snakes. Men eat hogs." 20 Los acontecimientos de la carrera de Dolores trazarán la parábola entera, empezando con el ascenso al poder y terminando con el descenso a la pobreza, punto inicial.

Como ocurre en la parábola sádica de la parte china, estas dos figuras efectúan la unión entre el nivel gráfico de la palabra y el nivel textual de los acontecimientos. La sección de Dolores Rondón es un diálogo teatral entre dos narradores que comentan sobre la vida de la protagonista. Antes de comenzar la historia, estos dos narradores entablan una discusión sobre la naturaleza del lenguaje. El Narrador Uno está en contra de la tradicional definición del lenguaje como medio de comunicación. No cree que el arte deba trasmitir moral alguna ni expresar ninguna esencia. En cambio, el Narrador Dos afirma su creencia en la finalidad utilitaria del lenguaje. El punto de partida de la discusión es la división clásica entre "palabra," y su "sentido justo" (propio), transmitido aquǐ por medio de la metáfora "perro/agua" (58). De esta problemática sobre la naturaleza del len- 
guaje surge la parábola de los animales, que se relaciona más tarde con el relato de Dolores: "las palabras son como las moscas, los sapos, como es sabido, se comen las moscas, las culebras se comen los sapos, el toro se come las culebras y el hombre se come al toro ..." (59). La figura del deseo/poder incluye en sí el movimiento sucesivo de los significantes en cadena, una palabra se traga a la otra, etc.

El diálogo inicial de los narradores está incluido dentro de la narración de los acontecimientos de la vida de Dolores, que se desarrollan según el "orden del poema" (58), la décima cincelada en la tumba de la mulata. Los movimientos de ascensión al poder serán los de la progresión de la décima. Cada línea trata de una etapa en el doble movimiento hacia la capital y hacia la fama. Como la narración equivale al tiempo de la enunciación de la décima, el tiempo y el espacio son verbales, como en la batalla erótico/teatral de la parte china. Este vínculo entre el nivel verbal y el textual de los sucesos se desplegará a través de toda la narración, y culminará en una parodia del género teatral.

Igual que la anterior unión entre el General y Auxilio en "Curriculum cubense," la relación entre Dolores y Mortal forma un binomio: “¿Los opuestos se juntan!” (61). De esta polaridad se lanza el movimiento, lineal y doble, de la parábola del poder, que tiene su comienzo en la provincia, cuando Mortal es candidato a concejal. Mortal pronuncia un discurso al pueblo, caracterizado por la retórica vacía del demagogo, que se relaciona con la problemática del lenguaje establecida por los dos narradores. La oratoria de Mortal, transmitida por radio, se mezcla con trozos de anuncios (65) -la "estática" confunde la "estética" anticuada del politicastro. Como el discurso de Mortal es ejemplo de un lenguaje utilitario, el Narrador Uno parodia la teoría del enunciado implícita en éste. Además, el primer narrador pone énfasis en el aspecto puramente retórico del discurso, en el sentido del arte de declamación pública en la tradición griega, 21 al señalar como Mortal emplea las clasificaciones de la antigua retórica para lograr convencer al público (65). En medio de la arenga de Mortal, atraviesa el perro, la palabra, por la plaza (66). La falta de sentido de la retórica del discurso lo indican las Parcas, al gritar “¿Agua! ¿Agua!” (69). Desde este punto, la figura del ascenso lineal de la Dolores se cumple con el éxito de Mortal en las elecciones. Cuando llega a ser senador, las dos lineas se cruzan: Dolores recorre el camino hasta la capital y llega a la cima de la jerarquia social. Con este ascenso finaliza la parábola: "Dolores ha llegado a su barroco" (76), al apogeo del poder. 
Pero, el movimiento de la figura da una vuelta completa al caer Dolores de la cumbre a su posición original, a la provincia y a la pobreza. La segunda figura, la de los animales, explica esta caìda. Por la impostura de Dolores, se desata la "Zoofagia cicloide" (77): al tratar de pasarse por una bailarina exótica, Dolores suscita el enojo del Presidente. El movimiento de la parábola se desencadena aquí al revés, empezando con la mujer, equivalencia del hombre en la cita anterior: "La mujer se come al toro" (78), es decir, al Presidente, quien "se come a la culebra" (78), al denunciar el engaño al Primer Ministro. Este devora al sapo, el Secretario del Primer Ministro, que, a la vez, destruye a Mortal, la mosca (79). Como ya se ha dicho, este deslizamiento equivale a la relación entre significantes en la cadena de la narración del texto mismo. Esta caïda del poder de la protagonista es, además, el último eslabón en una cadena de causalidad lineal, que corresponde a la tragedia clásica.

Del movimiento de la parábola viene la parodia de la tragedia como género literario. La misma estructuración del relato como pieza teatral había prefigurado el molde retórico de la finalidad trágica. Desde las Parcas, que funcionan como eco irónico del coro en la tragedia clásica, al comentar la vida de Dolores, hasta las declamaciones finales de la protagonista, se establece un tono de tragedia bufa. En lenguaje elevado, Dolores exclama contra el trascurso opuesto de la parábola: "Vuelve el río a la fuente, la luz a la aurora, la fiera herida al bosque" (63). Con el mismo tono "grandilocuente," anuncia su final, burla de los suicidios en las tragedias clásicas: " 'Puñal, sé breve. No repitas mi sangre." "(63). La mezcla del lenguaje popular típico de Dolores con el tono elevado retórico, y la repetición de estas exclamaciones, finaliza la parodia. A la vez se señala el aspecto retórico de la tragedia: “ ¿Toda tragedia es repetitiva! ¿Toda repetición es retórica!" (79). Esta doble equivalencia indica que la retórica, la organización formal del enunciado, es inseparable de la escritura. En sí, no conduce a una finalidad, es sólo estructuración retórica del relato. De nuevo, se regresa a la décima de la carrera de Dolores, que anunciaba una moral utilitaria: "y sólo se inmortaliza/el mal que se economiza/y el bien que se puede hacer" (57). Se niega esta finalidad moral al notar la función retórica de la décima como eje de la estructuración del relato. Se afirma, en cambio, la negatividad a la cual conduce el orden del poema: "todo llega a fenecer" (57). El lenguaje de la décima es clásico y esencial, adecuado a la expresión de la causalidad trágica. Pero la parodia de la tragedia que forma los acontecimientos de la vida de Dolores vacían el poema de 
significación transcendental.

La historia de Dolores Rondón, por lo tanto, no sirve ninguna $\mathrm{E}$ (sté)tica. La parábola del poder trazada por ella es, simplemente, juego verbal, cadena de significantes. Así es como lo comenta el Narrador Uno, que habǐa negado la utilidad de la narración para un supuesto lector al principio del relato: "dime de qué ha servido, de qué está sirviendo esta devoración en cadena, de qué sirve la vida de Dolores Rondón, de qué servirá su muerte" (86). La respuesta es que el lector seguirá en su "sopón soporífero" habitual (58), que la escritura terminará en "Nada. Deliciosa Nada batida con leche" (86). Las palabras en cadena terminarán de ser el momento en que se termine la lectura. El deseo verbal implica su propia cancelación, y, de nuevo, la escritura se hace un travestismo: parodia de la tragedia y parodia de sĩ misma, de la función del significante sin sentido utilitario, dentro de un texto también sin fin.

La tercera figuración erótica en De donde son los cantantes es motivada por el deseo de las Parcas por el General en la parte "blanca" del texto. En vez de formar una parábola, aquil el deseo se desdoblará por una lînea divisoria entre alma/cuerpo. Las Parcas son ambas cuerpos en busca del espíritu, masculino, que representa Mortal/Cristo, a la vez que cada una se divide en la forma dual que toma este deseo: Socorro es Fe (alma), Auxilio es Práctica (cuerpo). Esta división del deseo recrea el dualismo a la base de la filosofía occidental, materia/espíritu, que además corresponde a las dos partes del signo verbal, significante/significado. La inscripción del deseo en el texto será a través de un lenguaje empapado de la mïstica española. Las figuras serán creadas por palabras con sabor netamente castellano o de raiz arábiga. De este modo el dualismo de la religón católica que se refleja en el deseo de las Parcas, cuerpo/alma, se sitúa en un contexto histórico que es simplemente textura verbal.

Como Mortal es el "Verbo santiaguero" (121), el cuerpo-en-elverbo, el deseo de las Parcas por este Cristo invertido se cifrará en sus propios cuerpos. Por medio del lenguaje que recrea la historia entera, Socorro se vuelve texto fỉsico, material, donde se lee el deseo que la consume, texto/cuerpo labrado por la superficie verbal castellana. El texto es tela, escultura, madera, piedra-cada elemento evoca un aspecto distinto de la cultura española: "Se veía infanta, flor aragonesa, pájaro plateresco aliabierto, clavado, entre manzanas y cenefas mudéjares, grabada en la heráldica púrpura de las Cortes, escrita en el cielo de un grabado, ... . señalando el puerto de Cádiz" (91). Esta inscripción del deseo se repetirá a lo largo de "La entrada de Cristo en la 
Habana," pero antes la figura tomará la forma de batalla, como en la parte china. Aquí, el deseo de Mortal produce en Socorro el espiritu de soldado que caracteriza a éste como hijo de Castilla (92). Llevadas por el deseo hasta Ronda, corazón de Andalucía, las Parcas combaten metafóricamente con los bandoleros de la región (92-93). Ultrajadas, se hunden en el mundo erótico musulmán, donde, otra vez, el deseo inalcanzable causa el ansia de batalla.

Desde el interior del mundo árabe, pasan a ser columnas en el templo de Medina Az Zahara. La perífrasis cifra el deseo en sus cuerpos materiales, en esos textos: "Capiteles, no, birretes de madera agujereados de letras coránicas; el nácar de los textos se repite alrededor de las cabezas ..., arma loas y preceptos, y de esas simetrías estrelladas desciende un follaje negrǐsimo -las greñas de las Moritasentorchado a las columnas de mármol de sus cuerpos" (94). Esta textualidad material de los cuerpos de las Parcas corresponde a la corporeidad del texto, labrado por las figuras del lenguaje. Es por eso que, como dice Sarduy, "el lenguaje aparecerá como el espacio de la acción de cifrar, como una superficie de transformaciones ilimitadas." 22 Escritura/travestismo que ahora se hace tatuaje, por la doble inscripción de cuerpos=textos, en el texto/cuerpo.

De este movimiento de cifra de figuras retóricas, se desprende el deseo como dualismo entre alma/cuerpo, lanzado por la búsqueda recǐproca de un término por el otro. Después de la batalla con el capataz andaluz, substituto de Mortal, éste les deja a las Parcas un tapiz, representación del deseo que sufren Auxilio y Socorro. El tapiz es el texto de la ausencia del objeto del deseo: "estos oros traen sentido, lengua de Mortal hay en ellos. Mensaje hilado..." (97). Su contenido pictórico es un banquete renacentista, mezclado con elementos criollos: un príncipe (el rubio Mortal), un joven director de orquesta, los músicos que representan las tres razas (flauta china, mandolina y arpa europeas, tambor africano, 98-99). Además, las figuras de la Fe y la Práctica en el tapiz son una alegoría del catolicismo. Por esta combinación de elementos, el tapiz funciona también como representación de la Cuba ausente, que indica la red de figuras del tex to mismo de la novela. Pero en su primer significado, el tapiz indica la bifurcación entre el deseo erótico y el espiritual, representados por las figuras de la Fe y la Práctica. Roto en dos partes por la pelea entre las Parcas que lo querian poseer, el tapiz define el transcurso de este dualismo. Socorro, el alma, sufre las etapas de abnegación del cuerpo para lograr su deseo espiritual, la unión con Mortal/Cristo (99-100). En cambio, Auxilio, el cuerpo, se desboca 
por la indulgencia carnal como prostituta en palacio. Las dos desviaciones del deseo llegan a unirse, ya que cada Parca volverá a ser su representación en el tapiz después de finalizar el rumbo que les hace tomar el deseo. El exceso sensual lleva a Auxilio a la ruina, a la pobreza y a la vejez: "eras una vieja narizuda y biliosa" (102), como era la Práctica en el tapiz (98). De igual manera, la viáa purgativa de Socorro logra la unión mistica con el objeto de su deseo: "Gozaste de raptos, éxtasis, don de lágrimas;... (te cubrìas con las manos un seno y el sexo)" (102), igual que la postura de la Fe en el tapiz.

Como texto del deseo de las Parcas, el tapiz efectúa la unión entre el nivel gráfico y textual cumplida por el lenguaje en De donde son los cantantes. El contenido del tapiz forma una sintesis del texto mismo: el príncipe del banquete es Mortal, Hipo es el doble de Bruno, músico santiaguero, la orquesta es la "orquestica sivaica," de "Junto al río..." (33), que le da tono al deseo, igual que "la orquestica de mambo" (147) que anuncia el cruce entre vida y muerte para Cristo al final. A través del texto, la orquesta sirve para unir los dos planos del binomio deseo/muerte que surge de la relación entre erotismo y escritura. La representación de la orquesta, cultural, en el tapiz fija la función erótica del lenguaje, a la vez que recrea la sintesis del texto. Se establece una nueva equivalencia: el tapiz es la representación de De donde son los cantantes, mosaico verbal de Cuba, igualmente representado en el tapiz. Como significante, al tapiz le debe corresponder un significado. Socorro trata de encontrarlo al virar la tela al revés, igual que los Narradores en "La Dolores Rondón" buscaban "el sentido justo de la palabra" (58); pero sólo se ve el reverso del bordado, que aparece como una falsificación del original. El supuesto sentido queda incompleto porque hay un descosido-hueco, falta de centro- cerca del borde del tapiz. Lo que el tapiz representa no es un sentido transparente, como en el signo clásico. Al contrario, el tapiz es mero significante, materialidad. El sentido esencial que le falta se de una Cuba verídica, histórica, total -este centro ausente queda reducido a una imitación verbal de esa orquesta racial que lo compone.

La función del tapiz como texto y reflejo de la Cuba ausente lleva a la segunda modalidad establecida en De donde son los cantantes, la mutua afirmación y negación de un origen. Esta problemática surge en la presentación de la figura que lo sintetiza, el "Curriculum cubense," artificio de las razas. Esta dialéctica desplaza la idea del Ser Presente esencial contra el juego verbal basado en un origen ausente. La función del lenguaje recrea esta tensión, ya que se niega la esen- 
cialidad del ser cultural al mismo tiempo que se reproduce en una reducción verbal. Como ha escrito Roberto González Echevarria, "in Sarduy's novel we are always engaged in a search for a lost origin while acutely conscious... of its irrevocable absence...." 23 El texto de De donde son los cantantes responde la pregunta de la canción de Miguel Matamoros - los cantantes son blancos, negros, chinos- a la vez que se mantiene la forma de la pregunta en el título. ${ }^{24} \mathrm{~A}$ través de esta constante afirmación y negación verbal, se desenvuelve en el texto la problemática del origen cultural.

El reflejo de esta dialéctica está en las parodias de categorias transcendentales efectuadas en el transcurso del relato. Primeramente, se burla la idea del lugar del nacimiento como verdadero origen del hombre. En "La Dolores Rondón" la provincia aparece como fija y esencial, en contra de la vida variable de la capital. Los dos narradores comentan sobre el deseo de Dolores de marcharse del lugar natal. El primero toma el punto de vista de afirmación del origen, mientras que el segundo niega su importancia (opiniones que reflejan sus ideas sobre la función del lenguaje): "Narrador Uno: ¿Ya ves? Desprecia lo esencial, el lugar de su origen. Narrador Dos: Calla, estúpido, lo esencial está entre la guanábana y el mango" (60). Con esto se propone o la nada o el sexo como verdadero origen del hombre, eco de la Nada existente que es la escritura y eco del erotismo que surge de ésta.

Además de burlarse del lugar del origen, se efectúa una parodia de la historia. Al nivel verbal, los trozos de textos tomados de momentos claves de la historia de España producen una superficie verbal, que reduce la dimensión temporal al efecto momentáneo de la palabra. El ejemplo más representativo es el viaje de las Parcas y Cristo desde Santiago a La Habana, peregrinación que repite una constante en la historia cubana, ${ }^{25}$ pero transformada en parodia, ya que se altera el perfil geográfico de la isla. Elementos extraños a un ambiente tropical se atribuyen a los lugares descritos, creando una yuxtaposición de ambientes (eco de la mezcla de elementos chino/ cubanos evocados en "Junto al río..."): cerca de Las Villas hay fábricas de kirch (136), en Ciégo de Avila un subway (135), y nieve en La Habana (146). Al acercarse más a La Habana, se aproxima la muerte de Cristo y el final del texto - la irrealidad del paisaje corresponde a esta descomposición textual, cuya culminación es la nieve, que evoca el blanco de la página, la ausencia de trazos sobre el papel.

Como Santiago de Cuba es el punto de partida para las peregrinaciones en la historia de Cuba (pero Santiago, por supuesto, es 
tradicionalmente meta de peregrinaciones), es ahỉ donde se sitúa el origen de la cultura cubana. Específicamente, en Santiago empezó el arte musical en la isla, tal como lo narra Alejo Carpentier en $L a$ música en Cuba. El primer obispo de Cuba, Juan de Wite, trazó planes para una cantorĭa en la catedral de Santiago, que serïa acompañada de un órgano, en el siglo XVII. Pero no fue hasta mediados del siglo XVIII que un tal Miguel Velázquez, mestizo, fue organista en ella. ${ }^{26}$ Hipo, director de la orquesta del tapiz, y Bruno, organista de la catedral, reflejan este primer organista mulato. $\mathrm{El}$ origen verídico del arte se parodia en la escena en la catedral de Santiago en "La entrada de Cristo en la Habana," tomado de la descripción de Carpentier de la primera orquesta cubana: "En Santiago de Cuba habǐa ya, sin embargo, una pequeña orquesta de dos tocadores de pifano, un sevillano, tocador de violón, llamado Pascual de Ochoa, y dos negras libres, dominicanas, ... que eran las hermanas Micaela y Teodora Ginés. Esta orquesta, formada para las fiestas, también tocaba en las iglesias." 27 De este "origen" saca Sarduy la orquesta del tapiz, la figura de Bruno como "violinista jacarandoso," (115), las Parcas como organistas y beatas de coro, y la mulata Rita Plá, "santera y soprano" (115). Además de transformar el origen histórico de la primera forma artístia cubana, se niega la música como categoría cultural. El órgano de la catedral de Santiago, relacionado con un Tiempo absoluto de la historia, se vuelve mecánico, parodia del original: "¿Y esa musiquilla? Son los órganos mecánicos.... Que no se pare el rollo. El rollo ahuecado que es la música. El Tiempo como un pergamino giboso" (107). Con esta transformación se vacia el historicismo en el pensamiento de Carpentier, 28 sustituyéndose esta transcendencia por la reducción de la historia en el habla. Al comienzo de esta escena en la catedral, el lenguaje cambia de ser eco de la esencia religiosa española, a la lengua criolla, "chusma". El lenguaje cubano señala y evoca el verdadero origen cultural, como antes lo hacían los ecos de la poesía árabe y española. Esta modulación del lenguaje -de la literatura en el pasado a la lengua hablada en el presente- forja el juego de la ausencia/presencia del ser cultural.

Paralelo al dualismo del ser cultural está el planteamiento del ser individual o "personaje," categorias que se desplazan igualmente por medio de la actividad del lenguaje. En "Curriculum cubense," se juega contra y por la idea de la esencialidad del ser, junto con la análoga tensión entre ausencia y presencia del origen. Aquí se parodia el concepto existencialista del ser presente y la "situación" del 
hombre moderno, consciente de la muerte de Dios y de la problemática del ser: "La pregunta de los sesenta y cuatro mil dólares, la definición del ser. ... Esta es la situación: nos hemos quedado y los dioses se fueron .... Esta es la situación: nos fuimos y los dioses se quedaron" (12). El ser con definición nacional, "nosotros," ya no es posible. Al no quedar origen cultural, el ser está constantemente en flujo, y esto hace que el problema de la existencia de Dios se vea como superficial. Los dioses se van o se quedan, igual que el individuo vascila al faltarle un contexto social.

En "Junto al rǐo..." se repite la especulación filosófica sobre el problema del ser en la reunión de los chinos en el Changai. Paradójicamente, la esencia del ser está en la metamorfosis. Como lo explica la metáfora de los pájaros, no hay esencia definitiva, sino sólo cambio en la superficie del ser: "El ser de los pájaros no es el timbre del trino, sino las plumas cayendo a cada muda" (48). La impostura surge como el único ser posible: "Blancas, son otro pájaro en la nieve, la firma del primero; rojas, pez que se vuelve mariposa..." (48). Esta constante transformación del ser por medio del cambio exterior señala la idea del sujeto en De donde son los cantantes. Ya no hay personajes fijos, con individualidad propia, sino entes forjados por la palabra que cambian de nombre y de sexo, que adoptan otras máscaras. Si en el juego de significación la palabra es una máscara que tapa la falta de sentido, aquî̉ la disolución del sujeto se cubre por la continua metamorfosis -escritura/travestismo. Las dos esencias -el sentido de la palabra y el concepto de la personalidad - han sido reemplazadas. Era esta esencialidad que daba fijeza a la palabra, igual que seguridad al ser. Ya no hay vínculo entre el sujeto-autor y su creación verbal: las palabras aparecen como entidades relacionadas entre sí, y no como producto de un "centro emisor" que las organiza. 29 De esta relación análoga de desplazamiento, surge la ligazón entre ser esencial=fijeza y falso ser (impostura)=movimiento. Las equivalencias corresponden, además, al signo clásico, transcendente, fijo, y al signo neobarroco, puro significante en flujo. El personaje como máscara indica además la falsedad de la búsqueda erótica que nunca se dirige hacia un sujeto, y, por eso, es sádico por naturaleza: "En el fondo el sadismo carece de sujeto, es pura búsqueda del objeto."30 La impostura del ser corresponde, entonces, a la materialidad pura del significante y a la objetificación del erotismo, e indica la desintegración del sujeto-autor.

En la parte china la impostura del ser se expresó a través de una metáfora muda, en conjunción con el ambiente estático que carac- 
terizó lo chino. La polaridad entre impostura del ser y ser esencial trascurrirá a lo largo del texto, tomando una expresión distinta en cada raza. En "Dolores Rondón" esta problemática se revelará en el tono burlón del lenguaje popular: "El que no cambia se estanca" (74). La carrera de Dolores fue una falsificación de su ser esencial, provinciano. En La Habana, Dolores cambió de máscara, como los pájaros el plumaje, al teñirse y desrizarse el pelo, y al vestirse de lujo (73). Esta transformación se ve como "el orden de las cosas" (74) dentro de la declamación del poema. En cambio, las Parcas, columnas de carne en Medina $\mathrm{Az}$ Zahara, ofrecen el estatismo del ser fijo, esencial, que les causa la espera de Mortal (95). La fijeza y el deseo las hacen querer cambiar de ser: "Buscaron, ay, más no encontraron. Quisieron desistir, ser otras" (106). En el texto, Auxilio y Socorro incorporan la personalidad como máscara. Puras construcciones verbales, se les describe desde el principio por la exterioridad, a través de la perífrasis. Al comienzo de la novela, se ve a Auxilio envuelta en maquillaje, desde su cabello voluminoso que cubre las capas de pintura en la cara (11). Pero el estatismo de la pintura creada por la descripción figurativa se quiebra con la preocupación de la Parca por el problema del ser. Esta irrupción, metafórica, tiene su equivalencia en la grabación del sufrimiento en la máscara. Como le indica Socorro, "las lágrimas te han hecho un surco en las cinco primeras capas del maquillaje" "(11). Como las figuras que imprimen el texto, y cubren la falta de centro significativo, la máscara del ser se graba en la incapacidad de fijar un centro para la personalidad. Sin identidad sexual verdadera y sin presencia absoluta, el ser se hace continua impostura.

Al llegar a este concepto de la máscara de la personalidad, se completa el sistema de escritura como travestismo a todos los niveles. La palabra tapa la falta de sentido originario, reflejado en la ausencia de una historia o un tiempo esencial. Sin esta dimensión, el juego verbal hace superficie de la totalidad cultural. Igualmente, el sujeto, individualización de la cultura, se suplanta por el falso ser al descomponerse la noción de origen social. Como impostura, el ser es falso objeto del deseo. Las Parcas, indices verbales de este enmascaramiento, mueren sin lograr la consumación de ese deseo, reflejo de las parábolas eróticas producidas antes en el texto. Con el fin del deseo se produce el fin de su objeto, binomio deseo/muerte: la muerte de las Parcas corresponde a la destrucción del verbo Mortal/Cristo. Simultáneamente, ocurre el fin del texto, destrucción de la palabra que engendró el sistema de relaciones. Sólo queda en la memoria del 
lector esa inscripción, sostenida a lo largo del texto, del significante.

Las relaciones forjadas por la palabra figurativa producen en $D e$ donde son los cantantes una sincronía o sistema, cuya reducción son las polaridades del deseo, del origen, y del ser. Una ausencia en cada orden efectúa la transformación de la esencialidad:

$\begin{array}{ll}\text { Palabra } & \begin{array}{l}\text { (Falta de Significado) } \\ \text { Deseo (figuras parabólicas) }\end{array} \\ \text { Origen Verbal } & \begin{array}{l}\text { (Falta de origen cultural) } \\ \text { Lenguaje cubano } \\ \text { Intertextualidad }\end{array} \\ \begin{array}{c}\text { Máscara de la } \\ \text { Personalidad }\end{array} & \begin{array}{l}\text { Impostura del ser: } \\ \text { Metamorfosis-movimiento }\end{array} \\ \text { Máscara de la } & \text { Impostura del ser: }\end{array}$

Esta sistema de polaridades implica la destrucción de las categorias tradicionales de la literatura: el personaje, la cultura, el lenguaje comunicativo. El lenguaje neobarroco, basado en la carencia de centro significativo, produce la relación de erotismo entre palabra y deseo, que forman la base del sistema. Paradójicamente, al reemplazar estas categorias, se forjan unas nuevas dimensiones por el mismo lenguaje figurativo.

De donde son los cantantes forma, entonces, un conjunto verbal cuyo eje es una contradicción implícita en la actividad misma del lenguaje. Al minar la noción de "esencia," se elimina el "personaje" literario, junto con su desarrollo dentro de un contexto histórico y social ficticio. Pero el texto hace surgir entes artificiales verbales que "personifican," a la vez, la sintesis de una cultura, cuya historia es fijada por la palabra. La diacronía desenvuelta en la trama de la novela realista - producida por la relación entre el personaje en su momento histórico - se substitu ye en Sarduy por la sincronia verbalcompuesta por el mismo desplazamiento del sujeto y de la historia como categorias esenciales. La actividad de la literatura, en cambio, se mantiene en la misma problemática, de presentar las relaciones entre el hombre y la sociedad, sólo que estos conceptos han cambiado: no son absolutos, sino productos definidos por la activi- 
dad del lenguaje. Los cantantes del texto son, inscritos por el juego de significación: rito verbal (el Son de la Loma)- Cuba es, origen (des)compuesto en razas, la palabra es ... deseo, constantemente motivado por las figuras metafóricas. Al efectuar este cambio y modificar la idea de ficción, la escritura neobarroca, a la vez, sirve para destruir el lenguaje burgués, fundamento del realismo. Como explica el mismo Sarduy: ". . . ser barroco hoy significa amenazar, juzgar y parodiar la economía burguesa, basada en la administración tacaña de los bienes, en su centro y fundamento mismo: el espacio de los signos, el lenguaje, soporte simbólico de la sociedad, garantía de su funcionamiento, de su comunicación." 31 Vemos en el texto de De donde son los cantantes una Cuba verbal que parodia la sociedad que existǐa antes de la Revolución, y que señala la posibilidad de un arte revolucionario que transforme la función misma del lenguaje, del arte, $y$ del pensamiento.

Cornell University

ADRIANA MENDEZ

\section{NOTAS}

1. Michel Foucault, Las palabras y las cosas - una arqueología de las ciencias humanas, tr. Elsa Cecilia Frost (México: Siglo Veintiuno Editores, S. A., 1968), pp. 70-71, 73 .

2. Jacques Derrida, "Structure, Sign and Play in the Discourse of the Human Sciences," en The Languages of Criticism and the Sciences of Man, ed. Richard Macksey y Eugenio Donato (Baltimore: Johns Hopkins Paperback Edition, 1972), pp. 247-249.

3. Oswald Ducrot y Tzvetan Todorov, Dictionnaire encyclopédique des sciences du langage (Paris: Editions du Seuil, 1972), pp. 438-439. Ver también Severo Sarduy, Escrito sobre un cuerpo (Buenos Aires: Editorial Sudamericana, 1969), pp. 9-30.

4. Foucault, op. cit., y Severo Sarduy, Barroco (Buenos Aires: Editorial Sudamericana, 1974), pp. 53-54.

5. Roberto González Echevarria, "Interview/Severo Sarduy," Diacritics 2, no. 2 (1972), 42 y Barroco, p. 70.

6. Sarduy, Barroco, pp. 51, 74-75.

7. Ibid., pp. 70, 75, 100.

8. González Echevarria, "Interview," p. 44 y Sarduy, Barroco, p. 101.

9. Roland Barthes, Le plaisir du texte (Parǐs: Editions du Seuil, 1973), p. 88.

10. Sarduy, Escrito, p. 48.

11. Ibid., p. 48. 
12. "Puede decirse que tres razas ... depositaron sus caracteres psicológicos en Cuba: la blanca, la negra, y la amarilla, y si se quiere una cuarta, la cobriza o americana." Fernando Ortiz, Los negros brujos (Miami: Ediciones Universal, 1973), p. 10.

13. Severo Sarduy, De donde son los cantantes (México: Editorial Joaquin Mortiz, S. A., 1967), p. 19. Las referencias en el texto son a esta edición.

14. Octavio Paz, Conjunciones y disyunciones (México: Editorial Joaquinn Mortiz, 1969), p. 99. Idea desarrollada en el análisis de Justo C. Ulloa y Leonor A. de Ulloa, "Proyecciones y Ramificaciones del Deseo en 'Junto al Río de Cenizas de Rosa," "Revista Iberoamericana, 51 (1975), p. 573.

15. C. A. S. Williams, Outlines of Chinese Symbolism and Art Motives (Shanghai: Kelly and Walsh, Lmt., 1932), pp. 399-400, 409-410.

16. Ulloa, p. 574.

17. Sarduy, Escrito, p. 40. En el fetichismo, la "única meta es quizá la muerte, la anulación del objeto del deseo." Sarduy se hace eco aquí de ideas de Bataille, muy presentes, por otra parte, en toda la obra de Octavio Paz.

18. Ibid., p. 14.

19. Ibid., p. 13.

20. Wallace Stevens, Collected Poems (New York: Knopf, 1954), p. 78.

21. Ducrot y Todorov, p. 99.

22. Sarduy, Escrito, p. 52.

23. Roberto González Echevarria, "In Search of the Lost Center," Review '72 (Fall), p. 29.

24. Roberto González Echevarria, "Memoria de Apariencias y Ensayo de Cobra,"Eco 28, no. 3 (enero 1975), p. 247.

25. González Echevarria, "Lost Center," p. 30.

26. Alejo Carpentier, La música en Cuba (México: Fondo de Cultura Económica, 1946), pp. 21-23.

27. Ibid., p. 35.

28. Véase González Echevarriaa, "Memoria...," p. 247, para la parodia de Carpentier efectuada en Gestos (1963), la primera novela de Sarduy.

29. Sarduy, Barroco, p. 52.

30. Sarduy, Escrito, p. 14.

31. Sarduy, Barroco, p. 99. 
